\author{
Воденииков С. A., \\ Скачков B. A., \\ Иванов В. И., \\ Воденникова О. С.
}

\begin{abstract}
ВЛИЯНИЕ МЕТОДОВ ВОЛОЧЕНИЯ НА ФУНКЦИОНАЛЬНЫЕ ХАРАКТЕРИСТИКИ АЛЮМИНИЕВЫХ ТРУБОК ПРЕЦИЗИОННОЙ ТОЧНОСТИ
\end{abstract}

Изучено влияние волочения алюминиевых трубок прецизионной точности в безоправочном режиме, а также на закрепленной и подвижной оправках, на их геометрические, прочностные и упругие характеристики. Для обеспечения заданного уровня функциональных характеристик трубок данного типа предложен подход, основанный на статистическом описании указанных характеристик с оценкой степени их деформащионной анизотропии.

Ключевые слова: методы волочения, алюминиевые трубки прецизионной точности, функциональные характеристики, деформачионная анизотропия.

\section{1. Введекие}

Современные конструктивно-технологические решения теплообменных и газодинамических установок предполагают использование алюминиевых трубок прецизионной точности (по толщине стенок и искривлению осевой линии) с высокими прочностными и упругими характеристиками для эксплуатации в химически активных средах. Технологические методы обеспечения заданных требований достаточно сложны и базируются на статистическом описании характеристик, реализуемых после каждого технологического передела производства трубок. Возможность применения алюминиевых трубок в условиях агрессивных сред предполагает их поверхностную обработку с получением плотных коррозионностойких покрытий.

\section{2. Анализ литературньх данньх}

Одной из основных характеристик заготовок алюминиевых трубок является толщина стенки, которая определяет однородность жесткости трубок и их деформационное поведение в процессе волочения.

В работах [1-3] изложены методы расчета полей деформаций и напряжений в процессе деформационной обработки металлов и их сплавов. Однако в данных работах не приводятся методики оценки деформационной анизотропии и формирования геометрической точности труб в процессе их волочения. В работах [4, 5] предложена методика оценки формирования анизотропии упругих и прочностных характеристик в процессе сложного деформирования структурно неоднородных сред. Формирование деформационной анизотропии обусловлено явлением текстурирования металлов в процессе их обработки давлением [6].
Методы оценки статистических параметров модулей упругости и пределов прочности металлов и сплавов предложены в работе [7].

Для алюминиевых сплавов наиболее доступными, обладающими высокими коррозионностойкими свойствами, являются оксидные и фосфатные покрытия [8].

\section{3. Постановка задачи}

Для обеспечения упругих, прочностных и геометрических требований алюминиевых трубок необходимо построение статистических характеристик исходных заготовок, после волочения их в безоправочном режиме, на цилиндрических закрепленной и подвижной оправках, а также оценка степени деформационной анизотропии упругих и прочностных характеристик. Дальнейшее повышение механических характеристик и коррозионной стойкости предполагает формирование защитно-упрочняющихся покрытий.

\section{4. Методика расчета статистических параметров}

Проведенные исследования позволили установить, что толщину трубок $h$ можно представить в виде соотношения:

$$
h(\ell)=h_{\beta}(\ell)+h_{j}(\ell)
$$

где $\ell$ - текущая координата по длине трубки; $h_{\beta}(\ell)-$ периодическая функция; $h_{j}(\ell)-$ случайная функция с нулевым средним, удовлетворяющая условиям эргодичности.

Периодическая компонента $h_{\beta}(\ell)$ является гармонической и, в свою очередь, может быть представлена в виде [9]: 


$$
h_{\beta}(\ell)=A \cdot \cos (\omega \cdot \ell+\psi) \text {, }
$$

где $A, \omega, \psi$ - детерминированная амплитуда, круговая частота и фаза изменения толщины трубок соответственно.

Круговая частота $\omega$ в уравнении (2) задается соотношением:

$$
\omega=\frac{2 \pi}{T}
$$

где $T-$ период изменения толщины.

Случайная компонента $h_{j}(\ell)$ характеризуется корреляционной функцией [9, 10]:

$$
h_{j}\left(\ell_{i}\right)=D_{h} \cdot \exp \left(-\alpha^{2} \cdot \ell_{i}\right)
$$

где $D_{h}$ - дисперсия толщины стенки; $\ell_{i}-$ расстояние до рассматриваемой точки $i ; \alpha-$ положительная константа.

\section{5. Экспериментальная оценка функциональньх характеристик}

Для оценки статистических характеристик использовали представительные выборки толщины алюминиевых трубок, как по длине, так и по их количеству. Толщину стенок измеряли с точностью 0,001 мм по окружной координате на каждой фиксированной длине $\ell_{\kappa}$.

Статистическая обработка результатов полученных измерений для заготовок алюминиевых трубок диаметром 8,0 мм из сплава Д16Т позволила установить следующие значения параметров функций в формулах (2) и (4):

$$
\begin{aligned}
& A=0,041 \text { мм; } T=80 \text { мм; } \\
& D_{h}=0,2676 \cdot 10^{-3} ; \alpha=2,839 ; \psi=0 .
\end{aligned}
$$

При безоправочном волочении с вытяжкой 1,1 на первом переходе параметры формул (2) и (4) изменяются до значений:

$$
\begin{aligned}
& A=0,121 \text { мм; } T=96 \mathrm{мм} ; \\
& D_{h}=0,5876 \cdot 10^{-3} ; \alpha=1,193 ; \psi=0 .
\end{aligned}
$$

Волочение на цилиндрической закрепленной оправке с вытяжкой 1,27 на втором переходе обеспечивает выполнение параметров функций (2)-(4) в виде:

$$
\begin{aligned}
& A=0,012 \text { мм; } T=104 \mathrm{мм} ; \\
& D_{h}=0,0066 \cdot 10^{-3} ; \alpha=0,798 ; \psi=0 .
\end{aligned}
$$

Волочение на цилиндрической подвижной оправке с вытяжкой 1,34 на третьем переходе обеспечивает выполнение значений параметров формул в следующих пределах:

$$
\begin{aligned}
& A=0,011 \mathrm{MM} ; T=104 \mathrm{MM} \text {; } \\
& D_{h}=0,0057 \cdot 10^{-3} ; \alpha=0,714 ; \psi=0 \text {. }
\end{aligned}
$$

Из данных (5)-(8) следует, что безоправочное волочение увеличивает разнотолщенность трубок, а оправочное волочение - снижает. Волочение на подвижной оправке обеспечивает снижение разброса величин толщины стенки по сравнению с волочением на закрепленной оправке до $6 \%$. Однако фактическая стабилизация толщины стенки трубок приводит к искривлению осевой линии, что обусловлено несимметричностью зоны деформирования в фильере [1].

Для восстановления прямолинейности оси трубки необходимо ее обратная пластическая деформация. База обратной деформации должна соответствовать периоду $T=104$ мм, а уровень деформации - соотношению:

$$
\varepsilon_{\text {обр }}=\frac{1,31\left(D_{h}\right)^{0,5}}{A} .
$$

В процессе волочения формируется деформационная анизотропия структуры алюминиевого сплава трубки, степень которой определяется методами, изложенными в работе [6].

Прогнозирование упругих и прочностных характеристик алюминиевых трубок в условиях образования структурной анизотропии возможно с применением методов, представленных в работах $[4,5]$.

Количественная характеристика кристаллографических структур базируется на аналитическом оценивании кристаллографических осей кристаллов относительно лабораторных осей, связанных с анизотропией текстурированной трубки.

Наиболее широко используется описание таких ориентаций с помощью углов Эйлера $\varphi_{1}, \Phi, \varphi_{2}$, которые задают поворот кристаллографических осей $x_{1}, x_{2}$ и $x_{3}$ относительно лабораторных.

В каждом зерне текстурированной трубки положение кристаллографических осей является случайным. Поэтому углы Эйлера являются также случайными и характеризуются совместной плотностью распределения $f\left(\varphi_{1}, \Phi, \varphi_{2}\right)$, которая задается в области изменения углов $0 \leq \varphi_{1} \leq 2 \pi, 0 \leq \Phi \leq \pi$, $0 \leq \varphi_{2} \leq 2 \pi$.

Для нетекстурированного сплава распределение углов Эйлера определяется:

$$
f\left(\varphi_{1}, \Phi, \varphi_{2}\right)=\left(\frac{1}{8 \pi^{2}}\right) \cdot \sin \Phi .
$$


Текстура приводит к изменению плотности распределения углов Эйлера. В этом случае формула (10) может быть записана в виде:

$$
f\left(\varphi_{1}, \Phi, \varphi_{2}\right)=T\left(\varphi_{1}, \Phi, \varphi_{2}\right) \cdot\left(\frac{1}{8 \pi^{2}}\right) \cdot \sin \Phi
$$

где $T\left(\varphi_{1}, \Phi, \varphi_{2}\right)$ - текстурная функция [6].

Экспериментальная оценка влияния процессов волочения на упругие характеристики алюминиевых трубок из сплава Д16Т представлена в табл. 1.

Таблица 1

Модули упругости $E$ алюминиевых трубок по переходам волочения

\begin{tabular}{|l|c|c|}
\hline \multicolumn{1}{|c|}{ Вид обработки } & $\begin{array}{c}\text { Среднее значе- } \\
\text { ние } E \text {, ГПа }\end{array}$ & $\begin{array}{c}\text { Коэффициент } \\
\text { вариации I, \% }\end{array}$ \\
\hline Исходнан заготовка & 9,44 & 6,10 \\
\hline $\begin{array}{l}\text { Волочение на закрепленной } \\
\text { пправке с вытяжкой 1,27 }\end{array}$ & 10,51 & 3,90 \\
\hline $\begin{array}{l}\text { Волочение на неподвижной } \\
\text { пправке с вытяжкой 1,34 }\end{array}$ & 11,19 & 2,30 \\
\hline
\end{tabular}

Поверхностное упрочнение и повышение химической стойкости реализуется методами электролитического окисления в электролите, составленном из органических кислот [8]. Для уплотнения оксидного покрытия применялся процесс эматолирования.

Полученная толщина покрытия трубок составляла 15...50 мкм. Модуль упругости оксидированного слоя составляет 14...15 ГПа. Толщина покрытия по отношению к толщине стенки алюминиевых трубок составляет $10 \ldots 15 \%$.

С целью оценки влияния поверхностного покрытия выполнена оценка прогиба трубок при трехточечном изгибе на длине 560 мм под действием усилия 8,8 Н. В табл. 2 представлены значения прогибов трубок с покрытием и без него после трехпереходной деформационной обработки.

Таблица 2

Прогиб трубок при трехточечной схеме нагружения

\begin{tabular}{|c|c|c|c|}
\hline $\begin{array}{c}\text { Внешний } \\
\text { диаметр, мм }\end{array}$ & $\begin{array}{c}\text { Среднян толщина } \\
\text { стенки, мм }\end{array}$ & $\begin{array}{c}\text { Толщина оксидно- } \\
\text { го покрытия, мм }\end{array}$ & $\begin{array}{c}\text { Прогиб, } \\
\text { мм }\end{array}$ \\
\hline 5,950 & 0,360 & 0 & 13,06 \\
\hline 5,970 & 0,383 & 0,025 & 12,61 \\
\hline 6,840 & 0,420 & 0 & 10,50 \\
\hline 6,850 & 0,441 & 0,030 & 9,60 \\
\hline
\end{tabular}

Из анализа данных табл. 2 следует, что оксидное эматолированное покрытие снижает величину прогиба в среднем от 3 до 8 \%.

\section{6. Выводы}

Выполнена оценка влияния методов волочения на геометрические, упругие и текстурные характеристики алюминиевых трубок. Установлено, что волочение на подвижной оправке снижает разброс значений модуля упругости по сравнению с волочением на закрепленной оправке до $70 \%$. Рассмотрено влияние оксидного эматолированного покрытия на жесткость при трехточечном изгибе трубок.

\section{Литература}

1. Перлин, И. Л. Теория волочения [Текст]/ И. Л. Перлин, М. 3. Ерманок. - М.: Металлургия, 1971. - 449 с.

2. Тарновский, И. Я. Теория обработки металлов давлением [Текст] / И. Я. Тарновский, А. А. Поздеев. - М.: Металлургия, 1963. - 431 с.

3. Гун, Г. Я. Пластическое формоизменение металлов [Текст] / Г. Я. Гун. - М.: Металлургия, 1968. - 521 с.

4. Скачков, В. А. Деформационная анизотропия и накопление повреждений в композитах при сложном нагружении [Текст] / В. А. Скачков // Механика неоднородных структур. - Львов: ЛПИ, 1987. - С. 257.

5. Соколкин, Ю. В. Исследование процессов деформирования и разрушения композитных материалов и конструкций при сложном напряженном состоянии [Текст] / Ю. В. Соколкин, В. А. Скачков, М. Г. Танкеева, В. В. Леонтьев // Механика конструкций из композиционных материалов. - 1984. - С. 97-101.

6. Адамеску, Р. А. Анизотропия физических свойств металлов [Текст] / Р. А. Адамеску, П. В. Гельд, Е. А. Митюшов. - М.: Металлургия, 1985. - 235 с.

7. Богачев, И. Н. Введение в статистическое металловедение [Текст] / И. Н. Богачев, А. А. Вайнштейн, С. Д. Волков. - М.: Металлургия, 1972. $216 \mathrm{c}$.

8. Грилихес, С. Я. Оксидные и фосфатные покрытия металлов [Текст] / С. Я. Грилихес. - Л.: Машиностроение, 1985. - 95 с.

9. Ивахненко, А. Г. Предсказание случайных процессов [Текст] / А. Г. Ивахненко, В. Г. Лапа. Киев: Наука, 1971. - 416 с.

10. Колмогоров, А. Н. Теория вероятностей и математическая статистика [Текст] / А. Н. Колмогоров. - М.: Наука, 1986. - 535 с.

\section{ВПЛИВ МЕТОДІВ ВОЛОЧІННЯ НА ФУНКЦІОНАЛЬНІ ХАРАКТЕРИСТИКИ АЛЮМІНІЕВИХ ТРУБОК ПРЕЦИЗІЙНОÏ TОЧНОСТІ}

Вивчено вплив волочіння алюмінієвих трубок прецизійної точності під час режиму без оправки, а також на закріпленій та рухомій оправках, 
на їх геометричні, міцністні та пружні характеристики. Для забезпечення заданого рівня функціональних характеристик трубок даного типу запропоновано підхід, що засновано на статистичному опису зазначених характеристик після кожного технологічного переділу виробництва таких трубок з оцінкою ступеню їх деформаційної анізотропії.

Ключові слова: методи волочіння, алюмінієві трубки прецизійної точності, функціональні характеристики, деформаційна анізотропія.

Воденников Сергей Анатольевич, доктор технических наук, профессор, кафедра металлургии черных металлов, Запорожская государственная инженерная академия, Украина, e-mail: vodennikov_dom@mail.ru.

Скачков Виктор Алексеевич, кандидат технических наук, доцент, кафедра металлургии черных металлов, Запорожская государственная инженерная академия, Украина,

e-mail: Skachkov48@mail.ru.

Иванов Виктор Ильич, старший научный сотрудник, кафедра металлургии черных металлов, Запорожская государственная инженерная академия, Украина, e-mail: colourmet@zgia.zp.ua.
Воденникова Оксана Сергеевна, кандидат технических наук, доцент, кафедра металлургии черных металлов, Запорожская государственная инженерная академия, Украина, e-mail: vodennikov_dom@mail.ru

Воденніков Сергій Анатолійович, доктор технічних наук, професор, кафедра металургї чорних металів, Запорізька державна інженерна академія, Украӥна.

Скачков Віктор Олексійович, кандидат технічних наук, доцент, кафедра металургї чорних металів, Запорізька державна інженерна академія, Україна.

Іванов Віктор Ілліч, старший науковий співробітник, кафедра металургї чорних металів, Запорізька державна інженерна академія, Україна.

Воденнікова Оксана Сергївна, кандидат технічних наук, доцент, кафедра металургї чорних металів, Запорізька державна інженерна академія, Україна.

Vodennikov Sergii, Zaporozhye State Engineering Academy, Ukraine, e-mail: vodennikov_dom@mail.ru.

Skachkov Victor, Zaporozhye State Engineering Academy, Ukraine, e-mail: Skachkov48@mail.ru.

Ivanov Victor, Zaporozhye State Engineering Academy, Ukraine, e-mail: colourmet@zgia.zp.ua.

Vodennikova Oksana, Zaporozhye State Engineering Academy, Ukraine, e-mail: vodennikov_dom@mail.ru

УДК $621.891(045)$

Кіндрачук М. В.,

Ticos O. B.,

Стебелецъка Н. М.

\section{P03РОБKA ГРАДIEHTHИХ ПОКРИTTIB ДЛЯ НАКЛАДОК ГАЛЬМІВНИХ ПРИСТРОїв}

В роботі запропоновано використовувати композиційні матеріали, в основу створення яких покладено приниип додатного градієнта механічних властивостей. Виготовлено та проведено триботехнічні випробування таких композиційних матеріалів. У якості матриці запропоновано використовувати композииійний евтектичний сплав на основі сталі 12X18Н9T з урахуванням теплофізичних характеристик змічнювальних фаз. Обгрунтовано проведення поверхневої комплексної лазерної обробки поверхні з метою покращення структури та триботехнічних властивостей поверхневого шару.

Ключові слова: гальмівні пристрої, евтектичний сплав, сталь, $\mathrm{Ti} B_{2}, \mathrm{VC}$, теплофізичні властивості, лазерна обробка.

\section{Beтуп}

Фрикційні матеріали застосовують у фрикційних динамічних пристроях, до яких належать гальма, накладки, спеціальні опори ковзання, муфти, варіатори. Ці пристрої призначені для розгону (муфти зчеплення) і зупинки (гальма, ковзні опори ковзання) транспортних машин, а також для приводів технологічного устаткування (різні фрикційні муфти і регулятори) та передавання і змінення напряму руху.

Фрикційні матеріали працюють у важких умовах зношення за високих питомих навантажень (до 8 МПа), швидкостей ковзання (до 50 м/с) і температур, що можуть миттєво підвищуватися до температури $1200{ }^{\circ} \mathrm{C}$.
Механічна енергія рухомих елементів у разі гальмування переходить у теплову, а потім розсіюється. Теплова дія у сукупності з багаторазовими циклічними навантаженнями, нагріванням i охолодженням, термічними і силовими деформаціями, утворенням градієнта температур істотно впливає на кінетику тертя і зношення фрикційних матеріалів.

\section{2. Актуальність дослідження}

Матеріали гальмівних пристроїв працюють в умовах жорсткого контактного і температурного навантаження. Від їх надійності і працездатності напряму залежить безпека персоналу та третіх 